\title{
PERCEPTIONS OF WORKERS ON THE BENEFITS OF INSTITUTIONAL SOURCE SORTING: A CASE OF THE COUNCIL FOR SCIENTIFIC AND INDUSTRIAL RESEARCH- INSTITUTE OF INDUSTRIAL RESEARCH (CSIR-IIR), ACCRA, GHANA
}

\author{
A. B. Yeboah* , J. Adu-Ntim, J. Koranteng, T. A. Tagbor, A. \\ Aniagyei And C. Kwawu \\ (A. B. Y., J. K. \& T. A. T.: Materials and Manufacturing Division, CSIR-IIR, P. O. \\ Box LG 576, East-Legon, Accra; J. K. A-N.: West-End University College, Nglesh- \\ ie-Amanfro, Kasoa, P. O. Box AN 15402, Accra-Ghana; A. A.: Department of Basic \\ Sciences, University of Health and Allied Sciences, Ho, Ghana; C. K... Department of \\ Chemistry, Kwame Nkrumah University of Science and Technology, Kumasi, Ghana). \\ *Corresponding author's email: boniface.antwi@gmail.com
}

\begin{abstract}
The management of solid wastes at the workplace in Ghana is characterised by mixed wastes pickup delays, dustbin overflows and leakage of plastic bags into the environment. Benefits from the pilot of source sorting as a mitigation measure at the workplace are unavailable in literature. Hence, the study employed descriptive statistical tools to assess the advantages of a piloted source sorting system at the CSIR-IIR. The sampled size was 100 staff with an $80 \%$ questionnaire recovery rate. The analysis of data showed that, the implementation of segregation at source transformed the social approach of workers towards waste management. Most workers (97.7\%) preferred sorting their wastes at source irrespective of the location of the generation point. A congenial environment was created by the source separation infrastructure, which made staff worked better, (70\% responses). The majority of staff $(95.2 \%)$ confirmed the savings made by the Institute on the cost of landfilling. The sorting at source improved cleanliness of the compound (97.6\% responses) and eliminated open-air burning of wastes (95.1\% responses). In all, the source segregation was beneficial to the social, economic and environmental well-being of staff and management of the Institution.
\end{abstract}

Keywords: Institutional solid wastes management, source sorting, perceptions on wastes, clean environment, segregation of wastes.

\section{Introduction}

The generation of solid wastes is increasing with economic growth and urbanisation (Chen, 2018). These wastes are heterogeneous in composition and have diverse sources of generation, such as homes, markets, commercial areas, institutions, streets and many more (Abdel-Shafy and Mansour, 2018). Wastes found in homes are described as domestic wastes (Yoada et al., 2014) whilst those at the workplaces (Bartone, 1991) and academic institutions (Mbuligwe, 2002) are institutional wastes. The domestic and institutional wastes in addition to those from the markets, shops, and lorry stations form the municipal solid wastes, which are generated in everyday life activities (Mbuligwe \& Kaseva, 2006). Conventionally, these are managed by a combined 
effort of private companies and municipal assemblies in the developed and developing world due to the economic, social and environmental impact (Mohsenizadeh et al., 2020). The managers may landfill the mixed collected wastes or sort after collection and recycle the plastic on one hand whilst composting the organics on the other hand (Taylor \& Todd, 1995).

The sorting of solid wastes promotes recycling or reuse activities that convert the material into new products or forms such as manufacture of geopolymer cement, waste water detoxifier, and many others (Onyelowe et al., 2019). This prolongs the life cycle of the wastes whilst saving the scarce land from pollution during landfilling (Kumar et al., 2017). However, sorting the wastes after collection reduces the quality of the raw material since they become contaminated with organic waste during mixed collection. For this reason, companies adopt cleaning methods in the processing of plastic wastes, which makes recycling costly. Additionally, the volume of raw materials for recycling reduces since some of the contaminated wastes may not be easy to clean. This prolongs raw material processing time with a corresponding decline in recovery and recycling rates. Consequently, source separation of the wastes is preferred over the post-collection sorting since it will improve the quality and recovery time through the provision of clean plastics in larger quantities for recycling. For instance, source sorting of solid wastes was found to be a booster to the production and factory expansion of informal recycling sector in Dhaka Bangladesh (Matter et al., 2013). Through the segregation of solid wastes at source, high market valued and improved quality of recyclables became accessible to small-scale recyclers (Matter et al., 2013). Similarly, efforts at improving re- cycling activities in Malaysia showed that, public awareness and the provision of source sorting infrastructure at the door-step of waste generators were key to the success of segregation at source, which enhanced the availability of recyclables to industry (Otitoju \& Seng, 2014). And so, it is imperative that sorting of wastes at source is promoted through public awareness and provisions of dustbins in developing economies such as Ghana to improve recycling rates and reduce landfilling (Malik et al., 2015).

Currently, municipal solid wastes in Ghana are not formally sorted at source even though a few informal sorting through pilot programs are sited in some middle to low-income communities in the capital city of Ghana, Accra (Oduro-Kwarteng et al., 2016). However, research shows that, there is a general willingness amongst residents of the Cape Coast municipal assembly to source segregate generated wastes if the required education and dustbins were made available (Gyimah et al., 2021). Furthermore, households of unplanned residential areas in the Tamale (Abagale et al., 2012) and the Ga East municipal assemblies, (Abiti et al., 2017), informally source sorted $30.3 \%$ and $37.0 \%$ respectively, of generated wastes, which will improve with the formalisation and provision of logistics. Even though the sorting of solid wastes at source is on a small scale, there is the indication that support from government policies will spearhead a shift in developmental strategies to enhance the collection method.

The minimal gains in the domestic source sorting of generated wastes demonstrates that, a pilot at the workplace will yield meaningful results. A study of staff preferences towards the mode of waste collection at the work place showed a significant interest of workers to source separate their wastes for 
enhanced recycling activities (Antwi et al., 2019). The implementation of literature and survey findings by the provision of adequate twin-dustbin setups with different colour codes for the source separation of solid wastes at the CSIR-IIR, demonstrated a $65 \%$ source segregation of generated wastes (Antwi et al., 2020). This estimates the potential benefits that will be achieved on a scaled-up institutional source sorting process.

However, there are no scientific records of the benefits associated with institutional source segregation. For this reason, the study explored the quantitative research approach to provide a scientific evidence basis for the gains in institutional source separation.

\section{Purpose of study}

The study sought to identify the viewpoint of CSIR-IIR workers on the influence the source sorting pilot programme had on the workplace. It explored the social, economic, and environmental impacts, which described the sustainability measures of the programme. The responses will be the premier scientific evidence of the benefits of sorting workplace solid wastes at source.

\section{Experimental}

\section{Research questions}

The study was directed by the following questions:

(a) What is the social impact of source sorting at the workplace?

(b) What are the economic gains in source sorting?

(c) What are the environmental benefits of source sorting?

The CSIR-IIR, East-Legon, Accra was the study area. The choice of the Institute was based on the different social background of workers, which included different religious believes, places of residence, income levels and tribes. Hence, the data is a representation of the varied workers experiences. Questionnaires received approval from the Institutional ethical review committee prior to data collection.

\section{Study design}

A quantitative data collection method was adopted in the exploratory research design. Graphs were generated from tallies of administered questionnaires.

\section{Sampling and sample size}

Samples were randomly collected from the study area. The sample size was estimated from the Yamane formulae (Yamane, 1973). This arrives at the minimum sample size through a combination of population size and the margin of error.

The calculation of the sample size is outlined in Equation (1).

$n=\frac{N}{1+N(\varepsilon)^{2}}=\frac{107}{1+107(0.10)^{2}}=$

$\mathrm{n}=$ the minimum sample size; $\mathrm{N}=$ total population $=107 ;{ }^{\varepsilon}=$ margin of error $(10 \%)$

Hence, the minimum sample size will be 51 respondents.

\section{Data collection and analysis}

Sampling was randomly carried out at the CSIR-IIR in 20 working days with the administration of 100 questionnaires to improve recovery rate and ensure the minimum sample size was achieved. An estimated $80 \%$ questionnaire recovery rate was recorded which represented 80 pieces of the administered forms. Data interpretation followed the descriptive analysis method. Staff completed the questionnaires voluntarily 
at break times. A careful explanation of the questions was given to respondents who could not read or write. Forms were unmarked and responses were kept confidential.

\section{The instrument}

The instrument involved 13 statements, which were categorised into three to address the research questions. The categories sort to explore the social benefits of source segregation, the economic impact and environmental gains. The social impact examined the changes in behaviour, and routine schedules that were due to the separation at source for improved working conditions. The economic gains were investigated to identify the financial benefits in the adoption of source segregation. The environmental impact determined the influence of the waste management practices on cleanliness, good sanitation and improvement in air quality. The entire instrument sought to assess the social, economic and environmental impact of source sorting at the workplace.

\section{Data analyses}

Collected data was tallied on the Microsoft Excel sheet, exported onto the Statistical Package for the Social Sciences (SPSS) version 18 platform and analysed. Calculated percentages and frequencies were recorded in tables and grouped under the three research questions.

\section{Results and discussion}

What is the social impact of source sorting at the workplace?

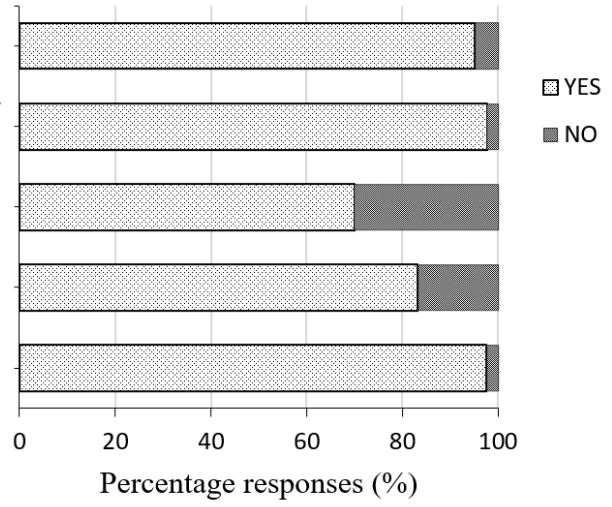

Fig. 1: Questions versus percentage responses to the social impact of source sorting. 
The influence of the waste collection practices on the social wellbeing of workers will enhance the sustainability of the source sorting in the Institute (Hellwig et al., 2019). The modification of the behaviour of waste generators towards disposal gives assurance of a socially sustainable waste collecting process (Hellwig et al., 2019, Oke, 2015). Data showed that, the majority $(97.7 \%)$ of waste generators would sort their wastes irrespective of the location, Fig. 1, which indicates a positive transformation in staff behaviour toward disposal of wastes (Hellwig et al., 2019). A supporting majority positive response $(97.6 \%$ responses) to the improvement in good sanitation practices at the offices indicates that, the collection method contributes to a healthier worker. Furthermore, the respondents worked better $(70.0 \%$ responses $)$ with no inconveniences in finding dustbins for source sorting of wastes during disposal, (83.3\% responses). This corresponds to an improvement in the social comfort of workers with consequential positive effects on the work output. Subsequently, the provision of waste collection logistics have lightened the work of managers (95.2\% responses) who experienced challenges with overflows of mixed wastes dustbins in the past. This shows that, source segregation grouped wastes into easy to collect portions that enhanced the management and transfers to recycling and composting plants. Hence, the source sorting of wastes was a convenient and healthy practice for both waste generators and collectors whose behaviours toward wastes were modified for a sustainable collection as recommended in the literature (Lin et al., 2017) .

What What are the economic gains in source sorting?

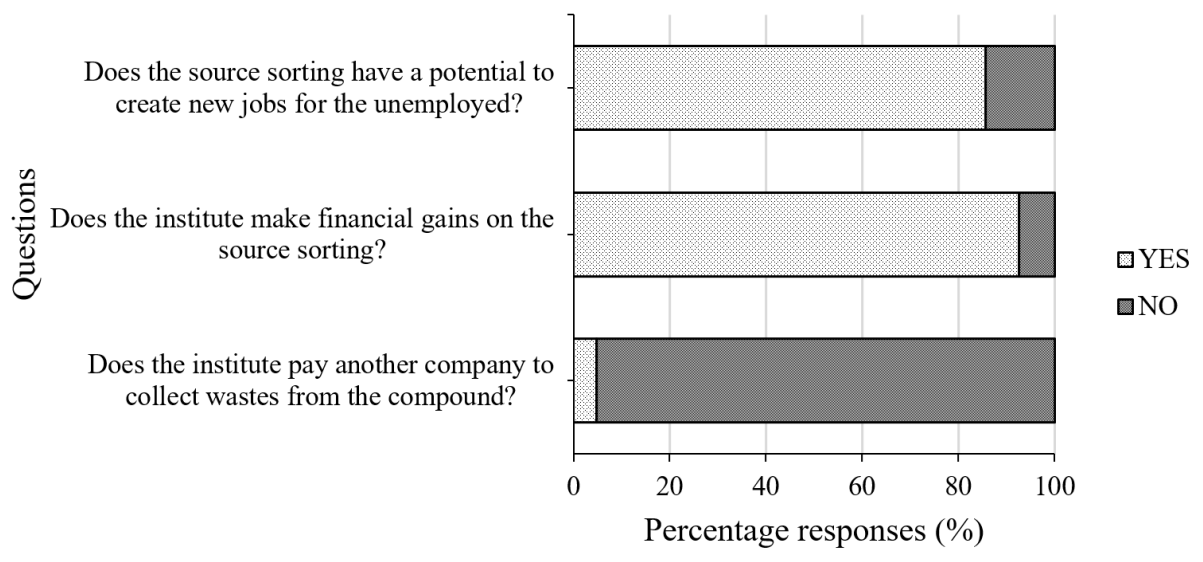

Fig. 2: A graph showing questions and responses on economic impact assessment. 
The growing demand for staffing and improvements in working conditions corresponds to a potential increase in wastes generation at the workplace (Senzige \& Makinde, 2015). This requires additional financing towards the provision of adequate dustbins and accessories for the collection of the wastes, as well as the cost of disposal. For this reason, the economic implications of shifting from the mixed to source sorting of wastes at the workplace were explored. The responses showed that, the Institute no longer contracted the services of private companies to landfill generated wastes, (95.2\% responses). Instead, the sorted plastics were recycled and the organics fed into biodigesters to generate biofuels. This saved the institute on the cost of disposal, which contributed to the financial gains on waste management, $(92.7 \%)$. Hence, the unfavourable financial commitments in landfilling the wastes coupled with collection delays were faced out during the source segregation at the Institute (Hong et al., 1993). Savings could be reinvested in the provision of infrastructure with an increasing staff population. This enhances the economic sustainability of the waste collection practice. Furthermore, the majority of respondents expressed affirmation of the job creation potentials that the segregation at source offered in the reuse and recycling process $(85.7 \%)$. This indicates that, the supply of plastic wastes raw materials was readily available to the companies through small collection agents who earned allowances from the purchase and sale of the wastes (e.g. plastic wastes). Therefore, the management practice enhanced the circular economy of the Institutional wastes through savings, recycling, and job creation opportunities, a situation that is similar to cost analysis of municipal wastes in Romania (Ghinea \& Gavrilescu, 2016).

What are the environmental benefits of source sorting?

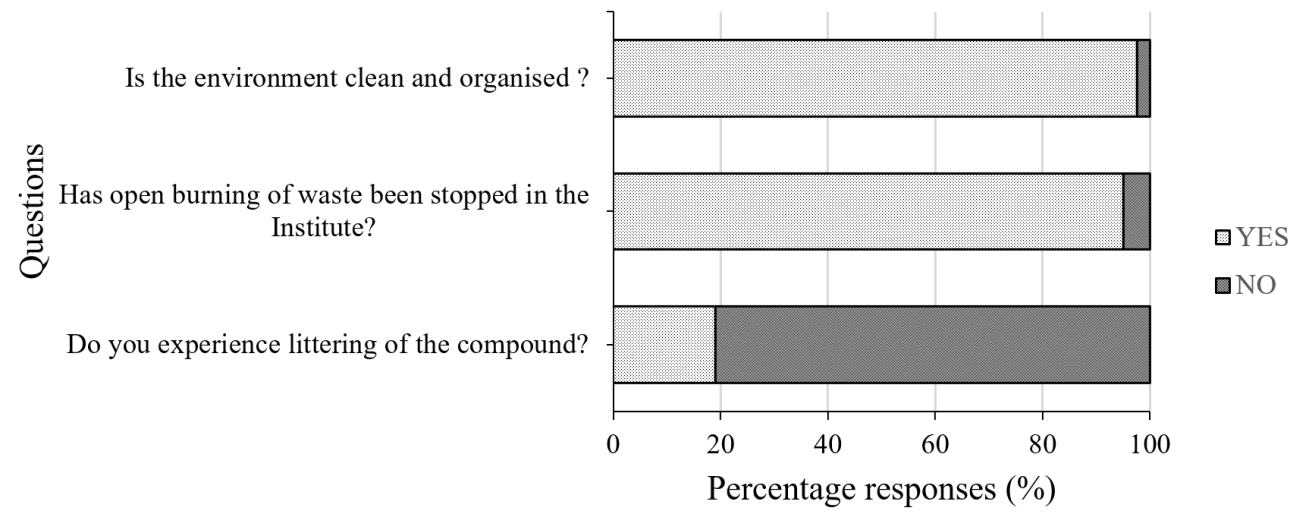

rig. 5: A grapn snowing vuestions and Keponses on environmentaı impact. 
The improper collection of solid wastes leaks plastics and papers into the environment, which causes pollution, as well as health hazards (David et al., 2020). The mixed collection of wastes at the Institute was characterised by delays in landfilling, dustbin overflows, and burning in the open. This contributed to insanitary working environment and the potential outbreak of diseases. On the other hand, the introduction of source segregation replaced the mixed collection method and demonstrated a safer alternative. The result from the quantitative study, Fig. 3, showed that, the separation at source reduced littering of the environment ( $81.0 \%$ respondents). This indicated that, the wastes were collected on time since there was no dustbin overflows that would litter the environment. Correspondingly, the regular burning of the wastes in the open stopped (95.1\% respondents) due to the high value of the plastic wastes as a resource for recycling and reuse activities. Hence, the respondents confirmed (97.6\%) the achievement of a cleaner and organised work environment. Therefore, the promotion of source segregation at the workplace guaranteed a cleaner and safer environment, which is consistent with literature (Zhao et al., 2011).

\section{Conclusion}

The perception of workers on the source sorting of institutional solid wastes has been assessed from the economic, environmental and social point of views. These have shown the implications of the waste management method on the well-being of workers since the welfare of staff determines the job satisfaction levels (Lissah et al., 2020).

The segregation at source caused a transformation in the attitude of workers towards solid wastes management with the willingness to sort wastes at source irrespective of the location, that is, in homes, or different workplaces. This was due to the informal education on the benefits and relevance of source segregation during the implementation of the pilot system. Additionally, the clean environment, which was assured by the absence of dustbin overflows and no delays in waste collection, provided safe surroundings at the workplace. This was enhanced by the absence of fumes and smoke from open burning of collected wastes since the practise was no more in place. The collection process did not only provide clean air and surroundings for workers but mitigated potential outbreak of diseases. With the recycling of sourceseparated plastic wastes and the in-house composting of organics, the institute made savings on the cost of waste management, which could be reinvested in the infrastructure when the need be. The provision of logistics, coupled with informal education of waste generators have positively influenced waste management at the workplace, which could be mimicked by other Institutions to save the environment and human lives whilst making financial gains.

\section{Acknowledgements}

The authors thank the staff and management of CSIR-IIR for the support and guidance in the research process.

\section{References}

Abagale, K. F., Mensah, A. \& Osei, R. A. (2012) Urban Solid Waste Sorting in a Growing City of Ghana. International Journal of Environment and Sustainability 1, 18 - 25.

ABDEL-SHAFY, H. I. \& MANSOUR, M. S. M.( 2018) Solid waste issue: Sources, composition, disposal, recycling, and valorization. Egyptian Journal of Petroleum 27, 1275 - 1290.

Abiti, B., Hartard, S., Bradl, H. B., Pishva, D. \& AHIAKPA, J. K. (2017) Resource Prospects 
of Municipal Solid Wastes Generatedin the Ga East Municipal Assembly of Ghana. Journal of health \& pollution 7, 37 - 47.

Antwi, B. Y., Koranteng, J., Odei, S. \& Anabila, E. (2020) Determinants of an Effective Solid Wastes Collection at the Workplace: the Experience of the Council for Scientific and Industrial Research-Institute of Industrial Research, Accra, Ghana. International Journal of Emerging Scientific Research 1, $20-27$.

Antwi, B. Y., OdeI, S. \& Anabila, E. (2019) A linear model for the collection of Institutional plastic wastes in Ghana: A case of the Council for Scientific and Industrial Research- Institute of Industrial Research (CSIR-IIR). Ghana Journal of Science $\mathbf{6 0}$, $32-41$.

BARTONE, C. R. (1991) Institutional and Management Approaches To Solid Waste Disposal in Large Metropolitan Areas. Waste Management \& Research 9, 525 - 536.

CHEN, Y-C. (2018) Effects of urbanization on municipal solid waste composition. Waste Management 79, 828 - 836.

David, V. E., John, Y. \& Hussain, S. (2020) Rethinking sustainability: a review of Liberia's municipal solid waste management systems, status, and challenges. Journal of Material Cycles and Waste Management, 22, 1299 $-1317$.

Ghinea, C. \& Gavrilescu, M.( 2016) Cost analysis of municipal solid waste management scenarios: Iasi-Romania case study. Journal of Environment Engineering and Landscape Management 24, 185 - 199.

GYIMAH, P., MARIWAH, S., ANTWI, K. B. \& ANSAHMENSAH, K. (2021) Households' solid waste separation practices in the Cape Coast Metropolitan area, Ghana. GeoJournal 86, $567-583$.

Hellwig, C., HäGgblom-KronlöF, G., Bolton, K. \& Rousta, K. (2019) HouseholdWaste
Sorting and Engagement in Everyday Life Occupations AfterMigration-A Scoping Review. Sustainability 11, 4901 - 4730.

Hong, S., Adams, R. M. \& Love, H. A. (1993) An Economic Analysis of Household Recycling of Solid Wastes: The Case of Portland, Oregon. Journal of Environmental Economics and Management 25, 136 - 146.

Kumar, S., Smith, S. R., Fowler, G., Velis, C., Kumar, S. J., Arya, S., Rena, Kumar, R. \& Cheeseman, C. (2017) Challenges and opportunities associated with waste management in India. Royal Society Open Science 4, 160764.

Lin, X., Maoliang, L., Yujie, L. \& Meng, S. (2017) Understanding Household Waste Separation Behaviour: Testing the Roles of Moral, Past Experience, and Perceived Policy Effectiveness within the Theory of Planned Behaviour. Sustainability 9, 625-652.

Lissah, S. Y., Ayanore, M. A., Krugu, J. \& Ruiter, R. A. C. (2020) Psychosocial Risk, WorkRelated Stress, and Job Satisfaction among Domestic Waste Collectors in the Ho Municipality of Ghana: A Phenomenological Study. LID - 10.3390/ijerph17082903 [doi] LID - 2903. International journal of environmental research and public health 17, 1660 - 4601.

Malik, N. K. A., Abdullah, S. H. \& Manaf, L. A.( 2015). Community Participation on Solid Waste Segregation Through Recycling Programmes in Putrajaya. Procedia Environmental Sciences 30, 10 - 14.

Matter, A., Dietschi, M. \& ZurbrüGG, C. (2013) Improving the informal recycling sector through segregation of waste in the household - The case of Dhaka Bangladesh. Habitat International 38, 150 - 156.

Mbuligwe, S. E. (2002) Institutional solid waste management practices in developing countries: a case study of three academic institutions in Tanzania. Resources, Conservation and Recycling 35, 131 - 146. 
Mbuligwe, S. E. \& Kaseva, M. E. (2006) Assessment of industrial solid waste management and resource recovery practices in Tanzania. Resources, Conservation and Recycling 47, 260 - 276.

Mohsenizadeh, M., Tural, M. K. \& Kentel, E. (2020) Municipal solid waste management with cost minimization and emission control objectives: A case study of Ankara. Sustainable Cities and Society 52, 101807.

Oduro-Kwarteng, S., Anarfi, K. P. \& Essandoh, H. M. K. (2016) Source separation and recycling potential of municipal solid waste in Ghana. Management of Environmental Quality: An International Journal 27, 210 $-226$.

OKe, A. (2015) Workplace Waste Recycling Behaviour: A Meta-Analytical Review. Sustainability 7, 7175 - 7194.

Onyelowe, K. C., Bui Van, D., Ubachukwu, O., Ezugwu, C., Salahudeen, B., Nguyen Van, M., Ikeagwuani, C., Amhadi, T., Sosa, F., Wu, W., Ta Duc, T., Eberemu, A., Pham Duc, T., Barah, O., IkPa, C., Orji, F., Alaneme, G., Amanamba, E., Ugwuanyi, H., Sai, V., Kadurumba, C., Subburaj, S. \& UGorJi, B. (2019) Recycling and reuse of solid wastes; a hub for ecofriendly, ecoefficient and sustainable soil, concrete, wastewater and pavement reengineering.
International Journal of Low-Carbon Technologies 14, 440 - 451.

Otıтоле, T. A. \& Seng, L. (2014) Municipal Solid Waste Management: Household Waste Segregation in Kuching South City, Sarawak, Malaysia. American Journal of Engineering Research 03, 82 - 91.

Senzige, J. P. \& Makinde, O. D. ( 2015) Modelling the Effects of Population Dynamics on Solid Waste Generation and Treatment. Science Journal of Applied Mathematics and Statistics 4, 141 - 146.

TAYLOR, S. \& TodD, P.( 1995) An Integrated Model of Waste Management Behavior: A Test of Household Recycling and Composting Intentions. Environment and Behavior 27, $603-630$.

YAmane, T. (1973) Statistics. An introductory analysis. Third edition, Harper \& Row.

Yoada, R. M., Chirawurah, D. \& Adongo, P. B. (2014). Domestic waste disposal practice and perceptions of private sector waste management in urban Accra. BMC Public Health 14, 697.

Zhao, Y., Christensen, T. H., Lu, W., Wu, H. \& WANG, H. (2011). Environmental impact assessment of solid waste management in Beijing City, China. Waste Management 31, 793 - 799.

Received 18 Sep 20; revised 16 Jul 21 